and Flame

Elsevier Editorial System(tm) for Combustion

Manuscript Draft

Manuscript Number: CNF-D-16-00567R2

Title: Ignition Delay Time Measurements of Primary Reference Fuel Blends

Article Type: Full Length Article

Keywords: Primary reference fuel; n-heptane; iso-octane; ignition delay times; shock tube

Corresponding Author: Professor Aamir Farooq, PhD

Corresponding Author's Institution: Clean Combustion Research Center, Division of Physical Sciences and Engineering, King Abdullah University of Science and Technology (KAUST), Thuwal 23955-6900, Saudi Arabia

First Author: Mohammed AlAbbad, M.S.

Order of Authors: Mohammed AlAbbad, M.S.; Tamour Javed, M.S.; Fethi Khaled, M.S.; Jihad Badra, Ph.D.; Aamir Farooq, PhD

Abstract: Ignition delay times of four different primary reference fuels $(\mathrm{PRF})$, mixtures of $\mathrm{n}$-heptane and iso-octane, were measured behind reflected shock waves in a high-pressure shock tube facility. The PRFs were formulated to match the RON of two high-octane gasolines (RON 95 and 91 ) and two prospective low-octane naphtha fuels (RON 80 and 70). Experiments were carried out over a wide range of temperatures $(700-$ $1200 \mathrm{~K})$, pressures $(10,20$, and 40 bar) and equivalence ratios (0.5 and 1). Kinetic modeling predictions from four chemical kinetic mechanisms are compared with the experimental data. Ignition delay correlations are developed to reproduce the measured ignition delay times. Brute force sensitivity analyses are carried out to identify reactions that affect ignition delay times at specific temperature, pressure and equivalence ratio. The large experimental data set provided in the current work will serve as a benchmark for the validation of chemical kinetic mechanisms of primary reference fuel blends. 
To: Editor Combustion and Flame

Ms. Ref. No.: CNF-D-16-00567

Title: Ignition Delay Time Measurements of Primary Reference Fuel Blends

Original files are embedded in the attached Word files. 
1

\title{
Ignition Delay Time Measurements of Primary Reference Fuel Blends
}

\author{
Mohammed AlAbbad ${ }^{\mathrm{a}}$, Tamour Javed ${ }^{\mathrm{a}}$, Fethi Khaled ${ }^{\mathrm{a}}$, Jihad Badra ${ }^{\mathrm{b}}$, Aamir Farooq ${ }^{\mathrm{a}}$ \\ ${ }^{\mathrm{a}}$ Clean Combustion Research Center, Physical Sciences and Engineering Division, King Abdullah University \\ of Science and Technology (KAUST), Thuwal, Saudi Arabia \\ ${ }^{b}$ Fuel Technology Division, R\&DC, Saudi Aramco, Dhahran, Kingdom of Saudi Arabia \\ *Corresponding author email: aamir.farooq@ kaust.edu.sa
}

\begin{abstract}
Ignition delay times of four different primary reference fuels (PRF), mixtures of n-heptane and iso-octane, were measured behind reflected shock waves in a high-pressure shock tube facility. The PRFs were formulated to match the RON of two high-octane gasolines (RON 95 and 91) and two prospective low-octane naphtha fuels (RON 80 and 70). Experiments were carried out over a wide range of temperatures $(700-1200 \mathrm{~K})$, pressures $(10,20$, and $40 \mathrm{bar})$ and equivalence ratios (0.5 and 1$)$. Kinetic modeling predictions from four chemical kinetic mechanisms are compared with the experimental data. Ignition delay correlations are developed to reproduce the measured ignition delay times. Brute force sensitivity analyses are carried out to identify reactions that affect ignition delay times at specific temperature, pressure and equivalence ratio. The large experimental data set provided in the current work will serve as a benchmark for the validation of chemical kinetic mechanisms of primary reference fuel blends.
\end{abstract}

Keywords: Primary reference fuel; n-heptane; iso-octane; ignition delay times; shock tube 


\section{Introduction}

The autoignition phenomenon is critical in improving the efficiency of combustion processes in spark ignition (SI) and compression ignition (CI) engines. For internal combustion engine design, efficiency and emissions are the two most important design parameters [1]. An obvious way to increase an engine's efficiency is to operate the engine at higher compression ratio. However, this results in increased probability of knocking, as the pressure and temperature of the end gas increase with an increase of the compression ratio. Knocking has been a key factor in limiting the improvement of efficiency in high compression ratio spark ignition engines for more than 60 years [2,3]. The presence and absence of knocking in a given engine depend mainly on the anti-knock quality of the fuel [4], which is conventionally defined by the fuel's octane number. Fuels with varying octane numbers may provide varying knock-limited compression ratios for an engine. Fuel chemistry and auto-ignition characteristics play an even greater role in modern engine designs such as homogeneous charged compression ignition ( $\mathrm{HCCI}$ ), partially premixed compression ignition (PPCI), and reactivity controlled compression ignition (RCCI). These engines are based on low-temperature operation and lean/stratified combustion to minimize soot and NOx emissions while simultaneously increasing the engine efficiency [5].

Fuel auto-ignition quality is commonly specified by research and motor octane numbers, RON and MON, respectively. These are determined by comparing the ignition of a given fuel with primary reference fuel (PRF), n-heptane/iso-octane, blends in standard knock tests. Gasoline consists of a large number of components, and its composition varies depending on the fuel's source and production history. Therefore, ignition characteristics of automotive fuels are often represented using surrogate fuels comprising of two or more components. One of the simplest surrogates that can be considered is a PRF blend. Practical fuels are very different from PRFs because they are complex mixtures of paraffins, aromatics, olefins, naphthenes and oxygenates. However, under certain conditions, the oxidation processes of PRFs can adequately represent the ignition and combustion characteristics of real fuels [6-8]. Although complex surrogates containing three or more components have been proposed in literature and can better represent chemical and physical characteristics of practical fuels, PRF blends remain the first choice of engine community for modeling real fuel properties [9-12]. This is due to the fact that the number of species and reactions increase tremendously for multi-component surrogates, making 
those impractical for use in computation fluid dynamic (CFD) simulations. Additionally, kinetic mechanisms of PRFs serve as the base mechanisms in the formulation of large multi-component chemical kinetic models. As a result, development of fully validated chemical kinetic mechanism of PRFs is critical for engine modeling.

There have been several experimental and modeling efforts on the ignition characteristics of neat n-heptane and iso-octane oxidative mixtures. However, blends of n-heptane and iso-octane, PRFs, have not been studied as extensively. Experimental ignition delay studies of pure nheptane, pure iso-octane, pure toluene and toluene blends are listed in Table 1, whereas experimental studies of PRF blends are listed in Table 2. In addition, relevant modeling studies are listed in Table 3. We would like to emphasize that despite the development of these many models for n-heptane/iso-octane, the validation data on the reactivity of PRF blends are quite limited.

\begin{tabular}{|c|c|c|c|c|c|}
\hline $\mathrm{S} / \mathrm{N}$ & Reference & Fuel & Temperature & Pressure & $\begin{array}{c}\text { Equivalence } \\
\text { Ratio }\end{array}$ \\
\hline 1 & $\begin{array}{l}\text { Vermeer et al. } \\
{[13]}\end{array}$ & $\begin{array}{l}\text { n-Heptane and iso- } \\
\text { octane }\end{array}$ & $1200-1700 \mathrm{~K}$ & $1-4$ bar & 1 \\
\hline 2 & Coats et al. [14] & n-Heptane & $1300-2000 \mathrm{~K}$ & $1-2$ bar & $0.5-4$ \\
\hline 3 & Ciezki et al. [15] & n-Heptane & $660-1350 \mathrm{~K}$ & $3.2-42$ bar & $0.5-3$ \\
\hline 2 & $\begin{array}{l}\text { Davidson et al. } \\
{[16]}\end{array}$ & iso-Octane & $855-1269 \mathrm{~K}$ & $14-59$ bar & 0.5 , and 1 \\
\hline 3 & $\begin{array}{l}\text { Mansfield et al. } \\
{[17]}\end{array}$ & iso-Octane & $740-1125 \mathrm{~K}$ & $3-30$ bar & 0.25 , and 1 \\
\hline 4 & $\begin{array}{l}\text { Gauthier et al. } \\
{[18]}\end{array}$ & $\begin{array}{l}\text { n-Heptane, } \\
\text { gasoline, and } \\
\text { TPRF }^{\text {a }}\end{array}$ & $850-1280 \mathrm{~K}$ & $\begin{array}{l}15-25, \text { and } \\
45-60 \text { bar }\end{array}$ & $0.5,1$, and 2 \\
\hline 5 & $\begin{array}{l}\text { Hartmann et al. } \\
\text { [19] }\end{array}$ & $\begin{array}{l}\text { Toluene, iso- } \\
\text { octane and } \\
\text { toluene/ n-heptane }\end{array}$ & $700-1200 \mathrm{~K}$ & 40 bar & 0.5 , and 1 \\
\hline 6 & Minetti et al. [20] & n-Heptane & $630-880 \mathrm{~K}$ & $2.7-4.5$ bar & 1 \\
\hline
\end{tabular}




\begin{tabular}{|c|c|c|c|c|c|}
\hline 7 & Herzler et al. [21] & n-Heptane & $720-1100 \mathrm{~K}$ & $50 \mathrm{bar}$ & $0.1-0.4$ \\
\hline 8 & Dagaut et al. [22] & $\begin{array}{l}\mathrm{n} \text {-Heptane, and } \\
\text { iso-octane }\end{array}$ & $550-1150 \mathrm{~K}$ & $10 \mathrm{bar}$ & $0.3-1.5$ \\
\hline 9 & Shen et al. [23] & n-Heptane & $786-1396 \mathrm{~K}$ & $9-58$ bar & $0.25,0.5$, and 1 \\
\hline 10 & $\begin{array}{l}\text { Davidson et al. } \\
\text { [24] }\end{array}$ & $\begin{array}{l}\text { n-Heptane and iso- } \\
\text { octane }\end{array}$ & $1100-1460 \mathrm{~K}$ & $1.6-2 \mathrm{bar}$ & $\begin{array}{l}\text { Oxidation } \\
(\phi=1) \text { and } \\
\text { pyrolysis }\end{array}$ \\
\hline 11 & $\begin{array}{l}\text { Davidson et al. } \\
\text { [25] }\end{array}$ & n-Heptane & $1300-1600 \mathrm{~K}$ & 2 bar & 1 \\
\hline 12 & Sakai et al. [26] & $\begin{array}{l}\text { n-hepane/ toluene, } \\
\text { iso-octane/ toluene } \\
\text { and } \mathrm{TPRF}^{\mathrm{a}} \text { blends }\end{array}$ & $1200-1600 \mathrm{~K}$ & 2.5 bar & 1 \\
\hline 13 & Javed et al. [27] & TPRF $^{\mathrm{a}}$ blends & $650-1250 \mathrm{~K}$ & $\begin{array}{l}10,20 \text {, and } \\
40 \mathrm{bar}\end{array}$ & 0.5 , and 1 \\
\hline
\end{tabular}

Table 1. Previous experimental studies of pure n-heptane, pure iso-octane, pure toluene and toluene blends. ${ }^{(a)}$ TPRF refers to iso-octane/n-heptane/toluene blends

\begin{tabular}{|l|l|l|l|l|l|}
\hline S/N & Reference & Fuel & Temperature & Pressure & $\begin{array}{l}\text { Equivalence } \\
\text { Ratio }\end{array}$ \\
\hline 1 & $\begin{array}{l}\text { Fieweger et al. } \\
{[3]}\end{array}$ & PRF 0, 60, 80, 90 & $700-1200 \mathrm{~K}$ & $40 \mathrm{bar}$ & 1 \\
\cline { 3 - 6 } & & iso-Octane & $700-1250 \mathrm{~K}$ & $13-40 \mathrm{bar}$ & $0.5,1$, and 2 \\
\hline 2 & Sarathy et al. [28] & PRF 84 & $715-1500 \mathrm{~K}$ & $\begin{array}{l}10,20 \text {, and } \\
40 \mathrm{bar}\end{array}$ & 0.5 , and 1 \\
\hline 3 & This work & PRF 70, 80, 91, 95 & $700-1200 \mathrm{~K}$ & $\begin{array}{l}10,20 \text { and } \\
40 \mathrm{bar}\end{array}$ & 0.5 and 1 \\
\hline
\end{tabular}

Table 2. Previous and current experimental ignition delay studies of PRF blends 


\begin{tabular}{|c|c|c|c|}
\hline $\mathrm{S} / \mathrm{N}$ & Reference & Model & $\begin{array}{c}\text { Number of species } \\
\text { / reactions }\end{array}$ \\
\hline 1 & $\begin{array}{l}\text { Westbrook et al. [29] } \\
\qquad(1989)\end{array}$ & $\begin{array}{l}\text { Detailed chemical kinetic reaction mechanism } \\
\text { for the oxidation of iso-octane, } n \text {-heptane and } \\
\text { their mixtures (PRF) }\end{array}$ & $212 / 765$ \\
\hline 2 & $\begin{array}{l}\text { Ranzi et al. }[30,31] \\
\quad(1995 \text { \& 1997) }\end{array}$ & $\begin{array}{c}\text { Semi-detailed kinetic scheme for n-heptane } \\
\text { oxidation }\end{array}$ & $145 / 2500$ \\
\hline 3 & $\begin{array}{l}\text { Curran et al. [32] } \\
\text { (1998) }\end{array}$ & $\begin{array}{l}\text { Detailed chemical kinetic mechanism for n- } \\
\text { heptane oxidation }\end{array}$ & $550 / 2450$ \\
\hline 4 & $\begin{array}{l}\text { Curran et al. [33] } \\
\text { (2002) }\end{array}$ & $\begin{array}{l}\text { Detailed chemical kinetic mechanism for iso- } \\
\text { octane oxidation }\end{array}$ & $860 / 3600$ \\
\hline 5 & $\begin{array}{l}\text { Tanaka et al. [34] } \\
\text { (2003) }\end{array}$ & $\begin{array}{l}\text { Reduced chemical kinetic mechanism for PRF } \\
\text { blends. }\end{array}$ & $32 / 55$ \\
\hline 6 & Jia et al. [35] (2006) & $\begin{array}{c}\text { Skeletal Chemical kinetic for iso-octane } \\
\text { oxidation }\end{array}$ & $38 / 69$ \\
\hline 7 & $\begin{array}{l}\text { Agafonov et al. [36] } \\
\qquad(2007)\end{array}$ & $\begin{array}{l}\text { Chemical kinetic mechanism for soot } \\
\text { formation during the pyrolysis and oxidation } \\
\text { of toluene and n-heptane. }\end{array}$ & $210 / 2250$ \\
\hline 8 & $\begin{array}{l}\text { Ahmed et al. [37] } \\
\quad \text { (2007) }\end{array}$ & $\begin{array}{l}\text { Comprehensive and compact chemical } \\
\text { mechanisms for } n \text {-heptane oxidation }\end{array}$ & $246 / 2309$ \\
\hline 9 & $\begin{array}{l}\text { Kirchen et al. [38] } \\
\text { (2007) }\end{array}$ & $\begin{array}{l}\text { Skeletal chemical kinetic mechanism for PRF } \\
\text { blends }\end{array}$ & $58 / 120$ \\
\hline 10 & $\begin{array}{l}\text { Ogura et al. [39] } \\
\qquad(2007)\end{array}$ & $\begin{array}{l}\text { Detailed chemical kinetic mechanism for the } \\
\text { oxidation of PRFs in the presence of ethyl- } \\
\text { tert-butyl-ether (ETBE) and ethanol }\end{array}$ & $634 / 2390$ \\
\hline 11 & $\begin{array}{l}\text { Andrae et al. [40] } \\
\qquad(2008)\end{array}$ & $\begin{array}{l}\text { Detailed chemical kinetic model of gasoline } \\
\text { surrogate fuels consisting of iso-octane, } n- \\
\text { heptane, toluene, di-isobutylene and ethanol }\end{array}$ & $1121 / 4961$ \\
\hline 12 & $\begin{array}{l}\text { Andrae el al. [41] } \\
\text { (2008) }\end{array}$ & $\begin{array}{l}\text { Semi-detailed chemical kinetic mechanism } \\
\text { for PRF oxidation }\end{array}$ & $137 / 633$ \\
\hline
\end{tabular}




\begin{tabular}{|c|c|c|c|}
\hline 13 & Ra et al. [42] (2008) & $\begin{array}{l}\text { Reduced chemical kinetic mechanism for PRF } \\
\text { oxidation }\end{array}$ & $41 / 130$ \\
\hline 14 & $\begin{array}{l}\text { Sakai et al. [43] } \\
\quad(2009)\end{array}$ & Detailed chemical kinetic model for TPRF ${ }^{a}$ & $783 / 2883$ \\
\hline 15 & Lee et al. [44] (2010) & $\begin{array}{l}\text { Reduced chemical kinetic mechanism for } \\
\text { TPRF }^{\mathrm{a}}\end{array}$ & $48 / 67$ \\
\hline 16 & $\begin{array}{l}\text { Mehl et al. [45] } \\
\quad \text { (2011) }\end{array}$ & $\begin{array}{l}\text { Detailed chemical kinetic model for gasoline } \\
\text { surrogate components }\end{array}$ & $1550 / 6000$ \\
\hline 17 & Liu et al. [46] (2012) & $\begin{array}{c}\text { Skeletal chemical kinetic models for PRF } \\
\text { oxidation }\end{array}$ & $41 / 124$ \\
\hline 18 & $\begin{array}{l}\text { Wang et al. [47] } \\
\text { (2013) }\end{array}$ & Reduced mechanism for PRF combustion & $73 / 296$ \\
\hline 19 & Cai et al. [48] (2015) & $\begin{array}{l}\text { Kinetic model for PRF blends based on the } \\
\text { optimization of reaction rate rules developed } \\
\text { previously by Curran et al. [33] }\end{array}$ & $314 / 2327$ \\
\hline
\end{tabular}

Table 3: Previous chemical kinetic mechanisms of pure n-heptane, pure iso-octane, pure toluene and their blends. ${ }^{a}$ TPRF refers to iso-octane/n-heptane/toluene blends

In the current work, we have measured ignition delay times of lean and stoichiometric PRF blends over a wide range of pressures $(10-40 \mathrm{bar})$ and temperatures $(700-1200 \mathrm{~K})$. The data encompass the negative temperature coefficient (NTC) region of the studied fuel blends. Four PRF blends are studied in this work. PRF 91 and 95 represent research octane numbers (RON) of common gasolines used in the US, Europe and Middle East. PRF 70 was chosen to represent light naphtha - a fuel that can potentially be used in gasoline compression ignition (GCI) engines. Finally, PRF 80 was chosen as an intermediate mixture to provide a range of $\mathrm{n}$ heptane/iso-octane mixture fractions that can be used to validate and improve chemical kinetic mechanisms of PRF blends. 


\section{Experimental Details}

Ignition delay times of primary reference fuel blends were measured using the high-pressure shock tube (HPST) facility at King Abdullah University of Science and Technology (KAUST). The shock tube is constructed from stainless steel with an inner diameter of $10 \mathrm{~cm}$. The driven section is $6.6 \mathrm{~m}$ long and the driver section has a modular design to vary its length from $2.2 \mathrm{~m}$ to a maximum of $6.6 \mathrm{~m}$. The mid-section of the shock tube houses two pre-scored aluminum diaphragms in a double diaphragm arrangement (DDA) which allows better control of the postreflected shock conditions compared to a single diaphragm arrangement (SDA). The main difference between DDA and SDA is the diaphragm rupture timing. In SDA, gas pressure in the driver section is increased until the diaphragm ruptures. The breaking pressure depends on many variables such as diaphragm thickness, scoring depth, aluminum grade and rate of pressure increase. This makes it hard to precisely control the bursting pressure $\left(\mathrm{P}_{4}\right)$ and ultimately provides varying conditions $\left(\mathrm{P}_{5}\right.$ and $\left.\mathrm{T}_{5}\right)$ behind reflected shock wave. In DDA, the mid-section is filled with bath gas pressure that is much lower than the breaking pressure of the diaphragm. Thereafter, the driver section is filled to the desired pressure $\left(\mathrm{P}_{4}\right)$. Breaking of the diaphragms is activated by suddenly venting the mid-section. This procedure allows precise control of postshock conditions and experimental conditions can be easily reproduced.

Incident shock speed was measured by six PCB 113B26 piezoelectric pressure transducers (PZTs) placed in the last $3.7 \mathrm{~m}$ of the driven section of the shock tube. Incident shock attenuation rates varied from 0.5 to $1.8 \% / \mathrm{m}$. Shock jump relations and known thermodynamic parameters [49] were used to calculate the post-reflected shock conditions $\left(\mathrm{P}_{5}\right.$ and $\left.\mathrm{T}_{5}\right)$ with an uncertainty of $<1 \%$. Sidewall pressure trace was measured using a Kistler 603B1 piezoelectric pressure transducer located at $1.0 \mathrm{~cm}$ from the endwall. Electronically excited $\mathrm{OH}^{*}$ chemilimuniscence at $307 \mathrm{~nm}$ was monitored through sapphire windows at the endwall using UV-intensified Thorlabs PDA36A photo-detectors. A schematic of the shock tube end-section is shown in Fig. 1. 


\section{Fig. 1. Schematic of the optical configuration for ignition delay time measurements.}

Liquid n-heptane and iso-octane were blended volumetrically to prepare the desired PRF blend. For example, PRF 80 consists of $80 \%$ iso-octane and $20 \%$ n-heptane by volume. Fuel/oxidizer mixtures were prepared in a heated $\left(75^{\circ} \mathrm{C}\right)$ magnetically stirred mixing tank. After vacuuming the mixing tank to pressures less than $1 \times 10^{-2}$ mbar, liquid fuel blend was injected directly in the heated mixing tank. The injection was made through a septa rubber valve that has high sealing properties. Following the fuel evaporation and pressure stabilization, the pressure was measured using an MKS pressure gauge ( 0 - 100 Torr range). Nitrogen and oxygen were added slowly to inhibit condensation of fuel that can lead to inaccuracies in the test mixture composition. Mixtures were left in the mixing vessel for at least one hour prior to experiments. High purity (99.9\%) n-heptane and iso-octane were purchased from Sigma Aldrich. Research-grade oxygen and nitrogen cylinders (99.999\% purity) were purchased from AH Gas Company. A molar ratio of 3.76:1 of $\mathrm{N}_{2}: \mathrm{O}_{2}$ was used to prepare fuel/air mixtures. Helium was used as the driver gas for ignition delay times less than $1.5 \mathrm{~ms}$. Driver gas tailoring (nitrogen in helium) and long length of driver section were used to extend the shock tube test times to more than $10 \mathrm{~ms}$. A gradual pressure rise behind reflected shock wave $\left(\mathrm{dP}_{5} / \mathrm{dt}\right)$ was observed, which varied from $2.5 \% / \mathrm{ms}$ to $3.5 \% / \mathrm{ms}$.

Ignition delay time is defined as the time between the arrival of the reflected shock wave and the onset of the ignition near the endwall. The arrival of the reflected shock wave was determined by the step rise in pressure at the sidewall $(1 \mathrm{~cm}$ from endwall) observation location. The onset of ignition was detected by the maximum slope in the sudden increase of pressure or $\mathrm{OH}^{*}$ endwall. 


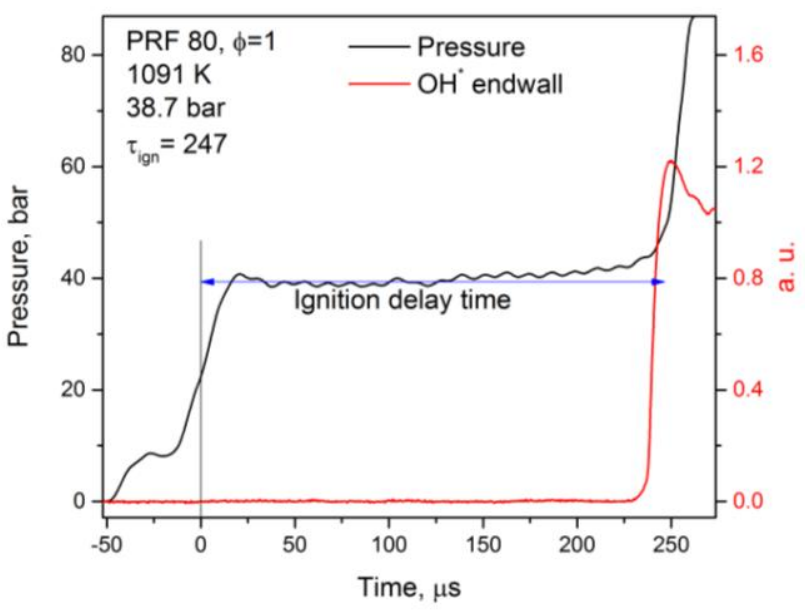

(a)

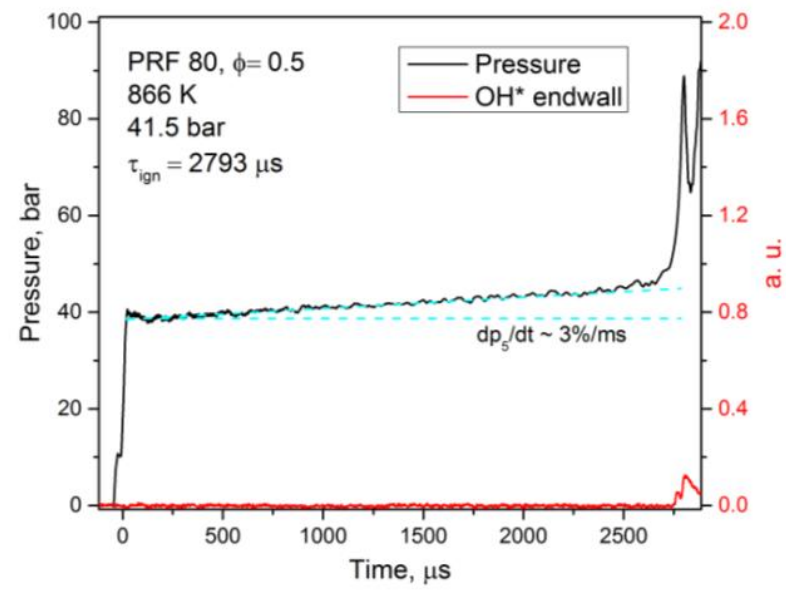

(b)

Fig. 2. Examples of pressure and $\mathrm{OH}^{*}$ emission-time histories for (a) non-tailored (He driver gas) shock and (b) tailored (mixture of $\mathrm{N}_{2}$ and He driver gas) shock.

\section{Results and Discussion}

Ignition delay times were measured for four PRF blends (PRF 70, 80, 91, and 95) over a wide range of temperatures $(700-1200 \mathrm{~K})$, pressures (10, 20 and $40 \mathrm{bar})$, and equivalence ratios $(0.5$ and 1.0). Measured ignition delay times are displayed in subsequent sections on Arrhenius-like plots, with the ignition delay on a log scale plotted as a function of reciprocal of reflected-shock temperature $\left(T_{5}\right)$. All experimental data are provided in tabular form in the Supplementary Material (Table S1). In subsequent sections, representative plots are given for the effect of pressure, equivalence ratio and fuel composition.

Ignition delay time simulations were carried out using CHEMKIN-PRO [50] with a homogeneous batch reactor. The gradual pressure rise behind reflected shock wave $\left(\mathrm{dP}_{5} / \mathrm{dt}=3 \%\right.$ $\mathrm{ms}^{-1}$ ) is converted to volume history and imposed on the homogeneous calculations. Ignition 
delay times from this study are compared with the predictions of four kinetic mechanisms; detailed gasoline surrogate mechanism of Mehl et al. [45], reduced PRF mechanism of Cai et al. [48], detailed PRF mechanism of Curran et al. [33], and detailed three-component (n-heptane, iso-octane, toluene) mechanism of Andrae et al. [40].

The sensitivity analyses presented in this work are calculated using the "brute-force" method. This involves increasing and decreasing the reaction rate coefficients by a factor of 2 and calculating the effect on the simulated ignition delay times. The sensitivity coefficient $(\sigma)$ is defined as:

$$
\sigma=\frac{\log \left(\frac{\tau+}{\tau-}\right)}{\log (4)}
$$

where $\left(\tau_{+}\right)$is the ignition delay time when the rate coefficient of the reaction is doubled and $\left(\tau_{-}\right)$ is the ignition delay time when the rate coefficient of the reaction is halved [51]. According to this definition, a reactivity promoting reaction results in a negative sensitivity coefficient and a reactivity inhibiting reaction results in a positive sensitivity coefficient. Unless otherwise specified, sensitivity analyses presented in subsequent sections are performed using the Mehl et al. [45] mechanism.

\subsection{Comparison with Previous Measurements}

Fig. 3( $a \& b)$ present a comparison among ignition delay times of PRF 80 and 91 from this work and PRF 80 and 90 from Fieweger et al. [3] and PRF 84 from Sarathy et al. [28]. It should be emphasized that both of these previous works measured the ignition delay times of PRF blends at limited ranges of conditions compared to the current work, as illustrated in Table 2. At high temperatures, there is excellent agreement among the ignition delay time measurements of the three works. Even at lower temperatures, there is a reasonably good agreement for the 20 bar as well as 40 bar cases. These comparisons ascertain the accuracy of the current data set. 


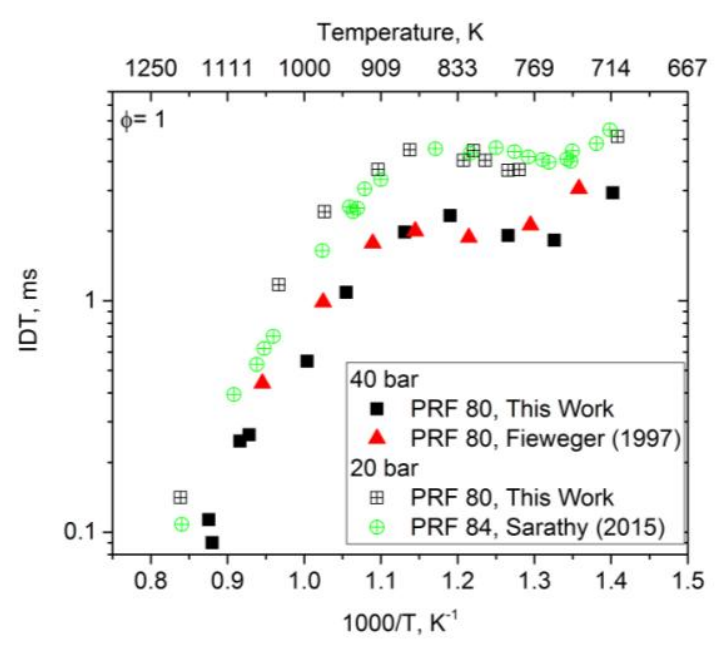

(a)

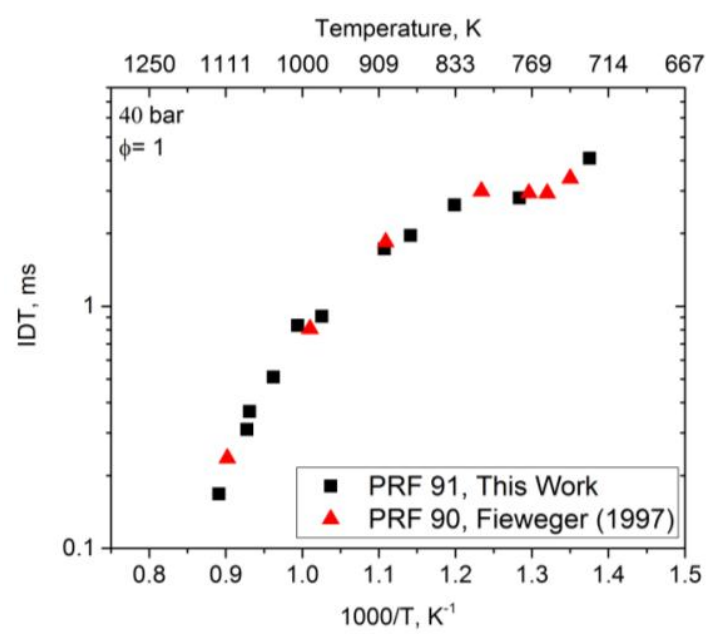

(b)

Fig. 3. Comparison of measured ignition delay times between this work and the data reported by Fieweger et al. [3] and Sarathy et al. [28].

\subsection{Ignition Delay Time Correlation}

For engine simulations, it is useful to have simple correlations that can represent the fuel autoignition behavior over a wide range of engine operating conditions. In the current work, we have developed ignition delay correlations in three steps. In the first step, we used the threeArrhenius model proposed by Wiesser et al. [52] for deriving the correlation of ignition delay times of pure iso-octane and n-heptane over $700-1300 \mathrm{~K}$ and $10-40$ bar. The Wiesser et al. [52] model correlates ignition delay times separately for the high-, intermediate- and lowtemperature reactivity regions. The low and intermediate ignition chemistries occur sequentially giving a two-stage ignition. However, at high temperatures, single ignition chemistry occurs. The ignition process may be illustrated with a simplified system, shown in Fig. 4, and written mathematically as:

$$
\begin{gathered}
\frac{1}{\tau_{j}}=\frac{1}{\left(\tau_{1}+\tau_{2}\right)}+\frac{1}{\tau_{3}} \\
\tau_{i}=A_{i} *\left(\frac{P}{P_{\text {ref }}}\right)^{\beta_{i}} * \Phi^{\gamma_{i}} * \exp \left(\frac{T_{a i}}{T}\right), \\
i=1,2 \text {, and } 3
\end{gathered}
$$


where $\tau_{1}, \tau_{2}$ and $\tau_{3}$ represent the low, intermediate, and high temperature ignition regimes, respectively, and $\tau_{\mathrm{j}}$ refers to the overall ignition delay of n-heptane $\left(\tau_{n-\text { heptane }}\right)$ or iso-octane $\left(\tau_{\text {iso-octane }}\right)$. Fitting parameters $\mathrm{A}_{\mathrm{i}}, \beta_{\mathrm{i}}, \gamma_{\mathrm{i}}$, and $\mathrm{T}_{\mathrm{ai}}$ are determined by regression analysis on the measured ignition delay data. Here, the ignition delay times of pure iso-octane and n-heptane were estimated from the available experimental data of the four PRF blends. The four fitting parameters were adjusted to fit the experimental data. The correlation parameters extracted from fitting Eqs. (1) - (2) to the experimental data are listed in Table 4. Values of the fitting parameters for the ignition delay time correlation of PRF blends.In the second step, we employed the ignition delay modeling approach proposed by Ma et al. [53] to include the effect of blending:

$$
\frac{1}{\tau}=\frac{x_{\text {iso-octane }}}{\tau_{\text {iso-octane }}}+\frac{x_{n-\text { heptane }}}{\tau_{n-\text { heptane }}}
$$

where $\mathrm{x}_{\text {iso-octane }}$ and $\mathrm{x}_{\mathrm{n} \text {-heptane }}$ are the molar fractions of iso-octane and $\mathrm{n}$-heptane, respectively, in the PRF blend. In the third step, we used Livengood-Wu [54] integral to account for the temperature/pressure change prior to ignition caused by the gradual pressure rise $(\mathrm{dP} / \mathrm{dt})$ behind reflected shock waves:

$$
\int_{0}^{\tau_{i g n}} \frac{1}{\tau(T, P)} d t=1
$$

where $\tau$ is the instantaneous ignition delay time as a function of pressure and temperature, and $\tau_{\text {ign }}$ is the total ignition delay time of the PRF blend. While applying this methodology to engine simulations, pressure and temperature time-histories of piston compression may be used in Eq. (4) to calculate the onset of knock. 


\begin{tabular}{|c|c|c|c|}
\hline n-Heptane & $\tau_{1}$ & $\tau_{2}$ & $\tau_{3}$ \\
\hline$A$ & $1.544 \times 10^{-13}$ & $2.15 \times 10^{5}$ & $1.2 \times 10^{-5}$ \\
\hline$\beta$ & -0.1 & -1.9 & -1.1 \\
\hline$\gamma$ & -0.1 & -0.8 & -0.3 \\
\hline$T_{a}$ & $2.2 \times 10^{4}$ & $-5 \times 10^{3}$ & $1.53 \times 10^{4}$ \\
\hline iso-Octane & $\tau_{1}$ & $\tau_{2}$ & $1.5 \times 10^{-5}$ \\
\hline$A$ & $2.21 \times 10^{-13}$ & $2.15 \times 10^{6}$ & -1.1 \\
\hline$\beta$ & -0.1 & -1.9 & -0.3 \\
\hline$\gamma$ & 0.1 & -0.8 & $1.53 \times 10^{4}$ \\
\hline$T_{a}$ & $2.2 \times 10^{4}$ & $-5 \times 10^{3}$ & . \\
\hline
\end{tabular}

Table 4. Values of the fitting parameters for the ignition delay time correlation of PRF blends.

Fig. 4 illustrates a comparison between the ignition delay times calculated from the correlations and the experimental data of this work. In general, the developed correlation does a reasonable job of modeling the measured ignition delay times. Such a correlation can be effectively used in simple computational fluid dynamic simulations of PRF blends. 


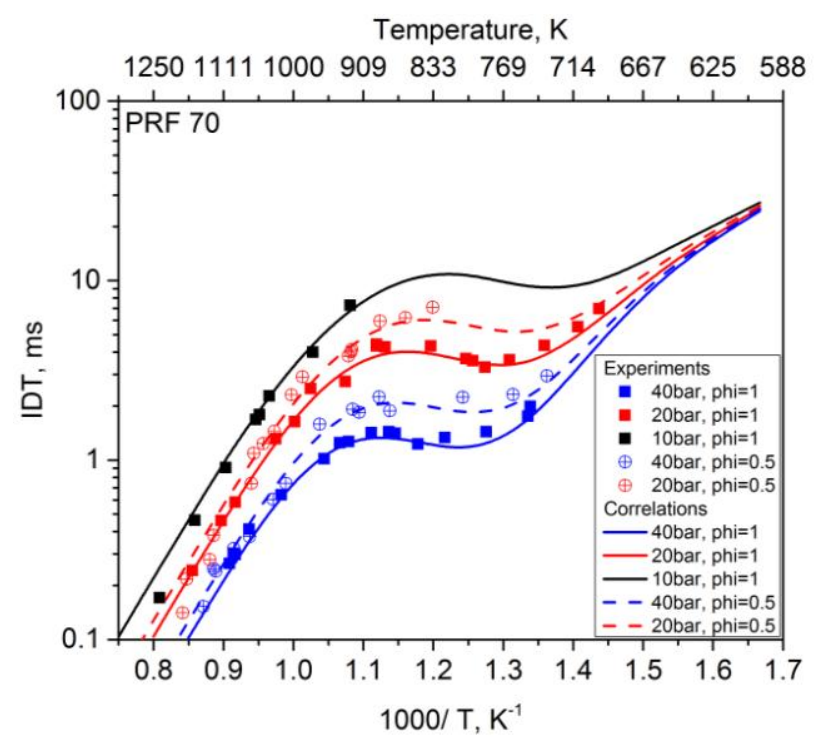

Fig. 4. Comparison between ignition delay time correlation and the experimental data of this work for PRF 70 blend.

\subsection{Influence of Pressure on Ignition Delay Times}

Ignition delay time measurements of the PRF blends were performed at pressures near 10, 20 and 40 bar. Fig. 5 ( $a, b$ and $c)$ present the effect of pressure on PRF $70(\phi=0.5$ and 1$)$ and PRF $91(\phi$ =1). As expected, ignition delay times of the PRF blends decrease with increasing pressure. Also, the pressure dependence increases as we move from the high-temperature to the NTC region. Moreover, the turnover temperature, marking the start of NTC region from the hightemperature side, increases with increasing pressure. The NTC is less pronounced at higher pressures due to the increased stability of $\mathrm{RO}_{2}$ radicals and faster decomposition of $\mathrm{H}_{2} \mathrm{O}_{2}$ at higher pressures. It can be observed that the pressure dependence is less for lean mixtures compared with stoichiometric mixtures. Fig. 5(c) also shows that larger concentration of isooctane in PRF 91 results in longer ignition delay times and less pronounced NTC reactivity. 


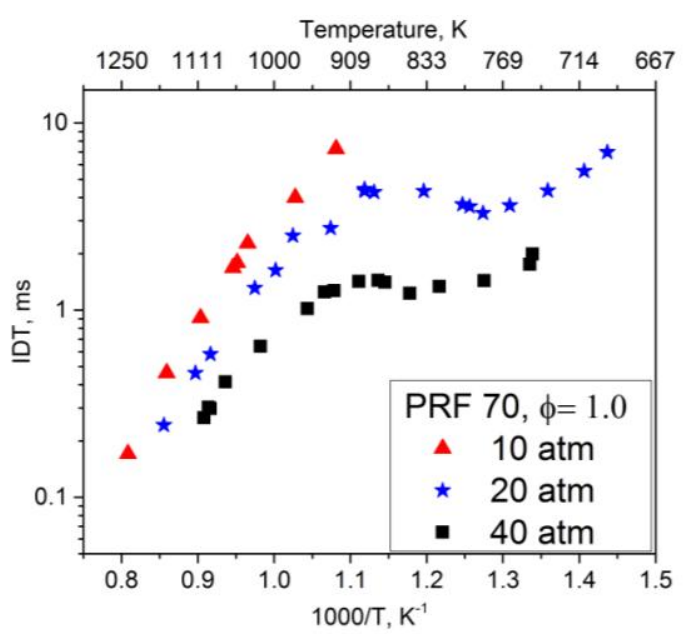

(a)

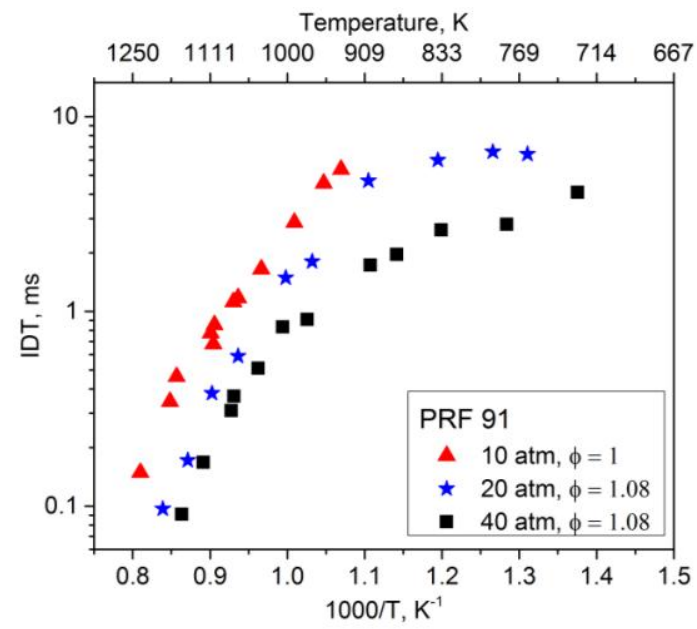

(c)

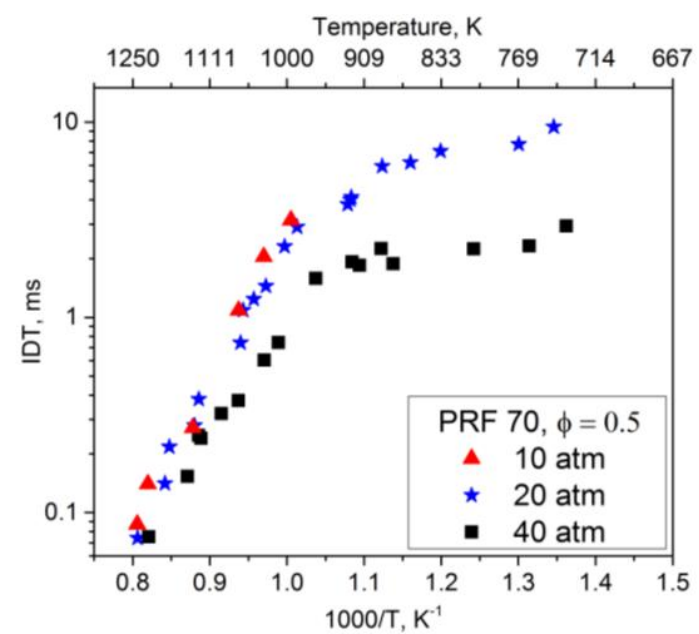

(b)

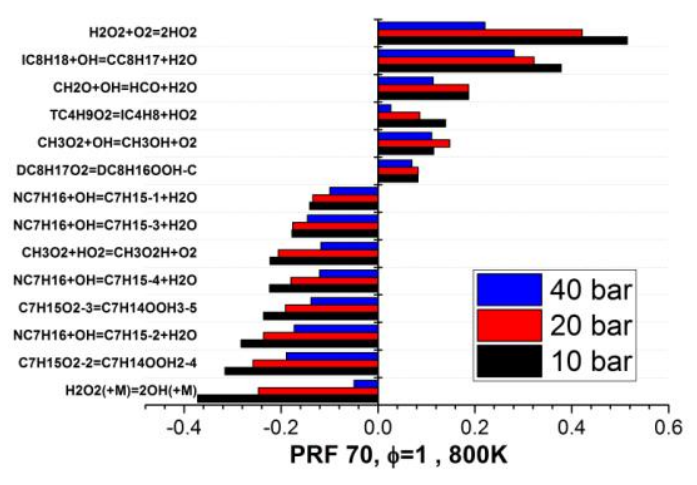

(d)

Fig. 5. Influence of pressure on ignition delay times. (a) PRF 70 ( $\phi=1)$, (b) PRF $70(\phi=0.5)$, (c) PRF $91(\phi=1),(d)$ brute-force sensitivity analyses for PRF $70(\phi=1)$ at $800 \mathrm{~K}$ using the Mehl et al. mechanism [45].

Sensitivity analysis was carried out at $800 \mathrm{~K}$ and three pressures (10, 20 and 40 bar) to elucidate the effect of pressure on reactions controlling auto-ignition. Critical reactions for stoichiometric PRF 70/air mixture are presented in Fig. 5(d). As pressure increases from 10 to 40 bar, the rate coefficient of the pressure dependent decomposition of hydrogen peroxide $\left(\mathrm{H}_{2} \mathrm{O}_{2}+\mathrm{M} \rightarrow 2 \mathrm{OH}+\right.$ M) becomes very fast and does not need to compete as much with the bimolecular reaction $\left(\mathrm{H}_{2} \mathrm{O}_{2}+\mathrm{O}_{2} \rightarrow 2 \mathrm{HO}_{2}\right)$. At lower pressures, these two reactions compete more effectively and thus 
the system reactivity decreases as pressure decreases. An interesting observation from sensitivity analysis is that the overall reactivity is more sensitive to the isomerization of $\mathrm{RO}_{2}$ radicals to $\mathrm{QOOH}$ than to the decomposition of hydrogen peroxide at 40 bar.

The pressure dependence exponents, $n$, have been calculated from the experiments and simulations over a temperature range between 700 and $1400 \mathrm{~K}$. Experimental pressure dependence exponents were calculated from the fitting of the measured ignition delay times. The fitting error was found to be $+/-20 \%$ and the variation of the fitting error with respect to temperature, pressure, equivalence ratio and fuel composition is shown in Fig. Sl (Supplementary Material). The pressure exponents were calculated from the 20 and 40 bar data, as follows:

$$
n=\frac{\log \left(\frac{\tau_{P=40}}{\tau_{P=20}}\right)}{\log \left(\frac{40}{20}\right)}
$$

Figure 7 show a comparison among the pressure exponents derived from the current experiments and the four kinetic models for PRF 70 stoichiometric and lean mixtures. As temperature increases from $\sim 850$ to $1250 \mathrm{~K}$, experiments show that the pressure exponents of the lean mixtures of PRF 70 decrease more sharply than the stoichiometric mixtures. The pressure exponents calculated from Curran et al. [33] and Andrae et al. [40] mechanisms decrease more gradually as temperature increases from 850 to $1400 \mathrm{~K}$. Cai et al. [48] mechanism shows higher pressure exponents than Curran et al. [33] and Andrae et al. [40]. Interestingly, the exponents calculated from Mehl et al. [45] mechanism decrease from 850 to $\sim 1000 \mathrm{~K}$ and then increase slightly from $\sim 1000 \mathrm{~K}$ to higher temperatures. The experiments and simulations show highest exponents in the NTC region due to the increased effect of pressure-dependent reactions such as hydrogen peroxide decomposition. Also, it may be observed that the pressure exponents decrease as we move from the NTC region to lower temperatures. Additional plots of pressure exponents for PRF 80 and 91 are given in the Supplementary Materials (Fig. S2). 


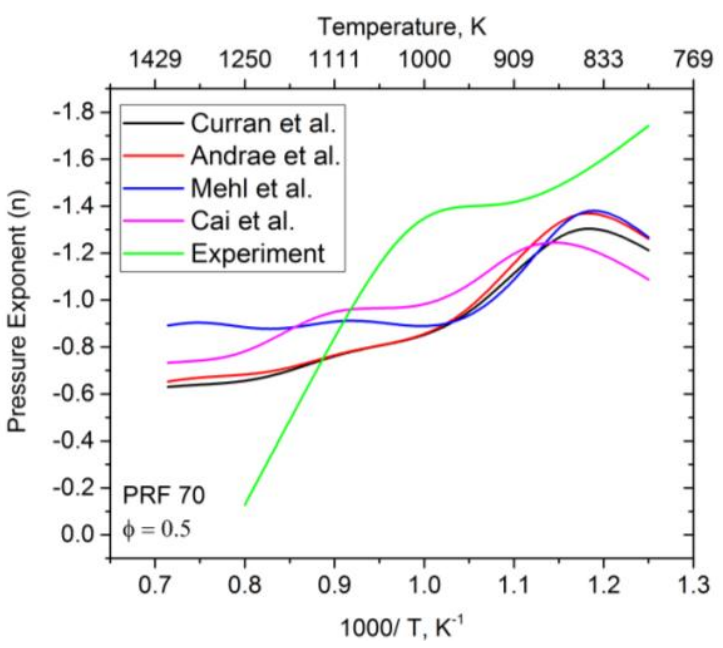

(a)

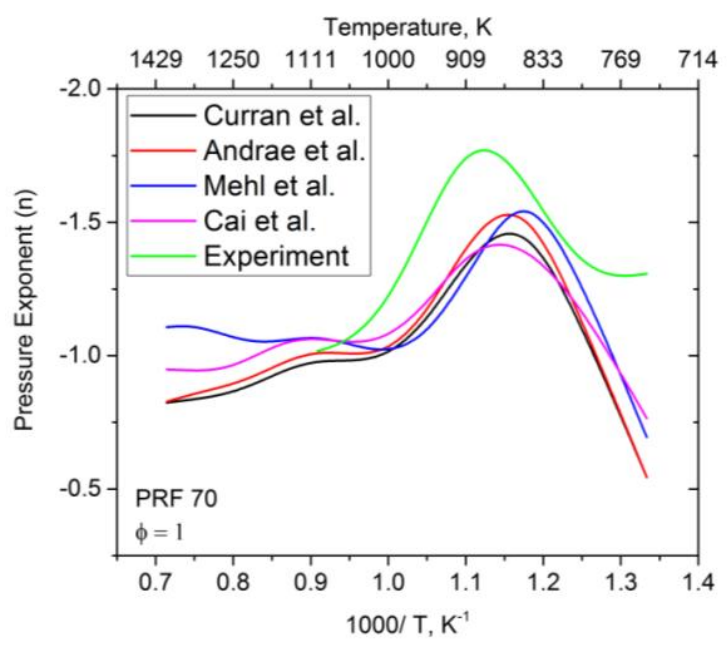

(b)

Fig. 6. Comparison of experimental and simulated pressure dependence exponents for PRF 70.

In order to elucidate the different pressure exponents predicted by the kinetic models at high temperatures, sensitivity analyses were conducted for PRF 70 at 1100 and $1200 \mathrm{~K}$; these analyses are given in Fig. S3 (Supplementary Material). At $1100 \mathrm{~K}$, the overall reactivity is sensitive to the reaction of atomic hydrogen and molecular oxygen to form hydroperoxide radical and the decomposition of hydrogen peroxide to form two hydroxyl radicals. At $1200 \mathrm{~K}$, the sensitivity coefficients of these reactions are smaller than at $1100 \mathrm{~K}$. Among the four models, Mehl et al. [45] and Cai et al. [48] mechanisms shows higher sensitivity to these reactions than Curran et al. [33] and Andrae et al. [40] mechanisms at $1200 \mathrm{~K}$. In other words, as temperature increases from 1100 to $1200 \mathrm{~K}$, the sensitivity coefficients of the pressure-dependent reactions decrease more for Curran et al. [33] and Andrae et al. [40] mechanisms compared to Mehl et al. [45] and Cai et al. [48] models. As a result, Curran et al [33] and Andrae et al. [40] exhibit lower pressure exponents at higher temperatures.

Variation of pressure exponents with fuel composition is shown in Fig. S4 (Supplementary Material) at $1100 \mathrm{~K}$. The experiments and the four mechanisms show an increase in the pressure exponents as we move to PRF blends with higher iso-octane concentration. This is due to the larger pressure dependence of iso-octane reactions compared with n-heptane at high temperatures (see sensitivity analysis in Fig. S5, Supplementary Material). 
Preceding analyses were based on the pressure exponents calculated from 40 and 20 bar data. Additional simulations were carried out to see how these exponents vary at lower pressures. Fig. S6 (Supplementary Material) shows that in the intermediate temperature $(850-1000 \mathrm{~K})$ region, the pressure exponents calculated from 40 and 20 bar data are larger than those calculated from 20 and 10 bar data. The trend is reversed at low temperatures $(<850 \mathrm{~K})$ where pressure exponents are larger for 20 and 10 bar data. This behavior could be explained based on the variation in pressure-dependent reactions across the two temperature regimes.

\subsection{Influence of Equivalence Ratio on Ignition Delay Times}

Ignition delay times for all PRF blends were measured at fuel lean $(\phi=0.5)$ and stoichiometric conditions. Figure $8(a)$ shows a representative case for the effect of equivalence ratio for PRF 70 at a nominal pressure of 40 bar. The effect of equivalence ratio is strongest in the intermediate temperature range where reactivity increases as $\phi$ increases. At higher and lower temperatures, ignition delay times exhibit weak dependence on equivalence ratio. Sensitivity analyses were carried out for PRF 70 at $800 \mathrm{~K}$ and 40 bar for lean and stoichiometric mixtures. At moderate temperatures, hydroperoxyl radical chemistry plays very important role. At lean conditions, the reaction of hydrogen peroxide with oxygen plays strong inhibiting role. Also, the sensitivity coefficients of the important reactions inhibiting the reactivity are higher for lean mixtures compared to the stoichiometric mixtures - illustrating the observed smaller reactivity for lean mixtures. 
Equivalence ratio dependence exponents, $m$, have been calculated from the experiments and kinetic models at 40 bar according to the following equation:

$$
m=\frac{\log \left(\frac{\tau_{\phi=1}}{\tau_{\phi=0.5}}\right)}{\log \left(\frac{1}{0.5}\right)}
$$

Fig. 7 shows comparison among the equivalence ratio exponents calculated from experiments and simulations. In general, the equivalence ratio exponents calculated from the experiments are found to be smaller than those from the simulations. The experiments and simulations show that the exponents are highest at intermediate temperatures $(\sim 850 \mathrm{~K})$ and decrease as we go to high temperatures or to low temperatures. For fuel/air mixtures, the variation in equivalence ratio results in varying fuel concentration and almost constant oxygen concentration. At high temperatures, the overall reactivity is controlled by competition between $\mathrm{H}+\mathrm{O}_{2}$ branching reaction and $\mathrm{CH}_{3}+\mathrm{CH}_{3}$ termination reaction, as seen in the sensitivity analysis presented in Fig. S7 (Supplementary Material). As temperature increases in this region, the $\mathrm{H}+\mathrm{O}_{2}$ reaction becomes more dominant compared to the fuel-dependent methyl recombination reaction and thus 


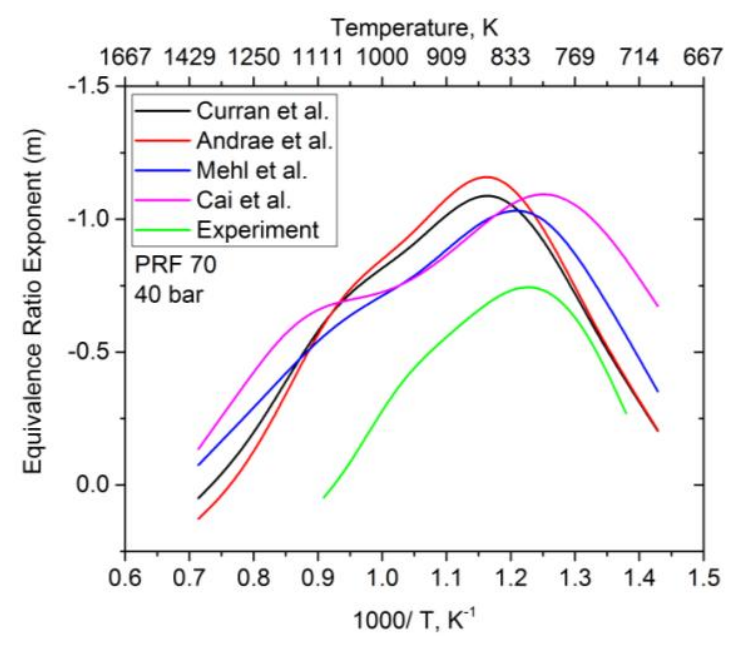

(a)

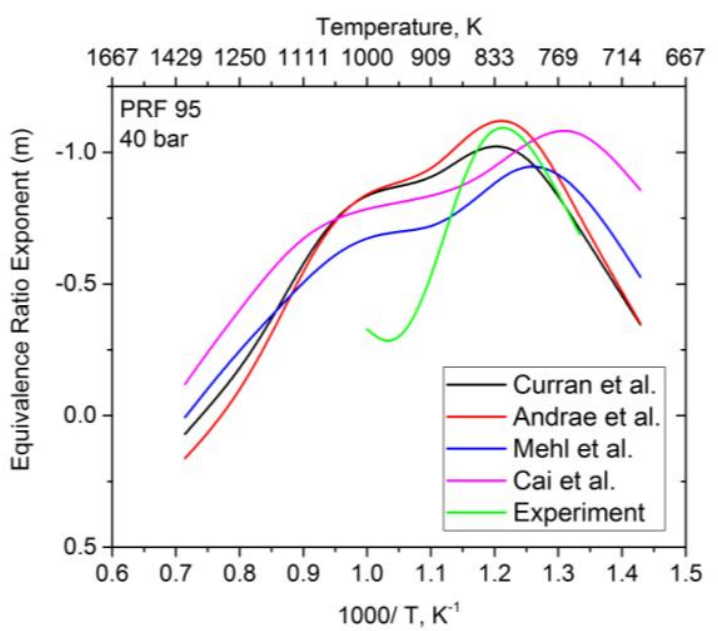

(b)

Fig. 7. Comparison between the equivalence ratio dependence exponents $(m)$ calculated from experiments and simulations

\subsection{Influence of Composition on Ignition Delay Times}

Fig. 8(a) illustrates the variation in ignition delay times for PRF 70, 80, 91 and 95. Results show that ignition delay times are almost independent of composition in the high-temperature region. In other words, at fixed pressure and equivalence ratio, the ignition delay times for PRF 70, 80, 
91 and 95 are quite similar at high temperatures. However, the composition does have an appreciable effect at intermediate temperatures $(\sim 700-900 \mathrm{~K})$. Increasing the iso-octane fraction (PRF 70 to PRF 95) results in a decrease of overall reactivity and consequently longer ignition delay times. At further lower temperatures $(<700 \mathrm{~K})$, ignition delay times are less sensitive to fuel composition.

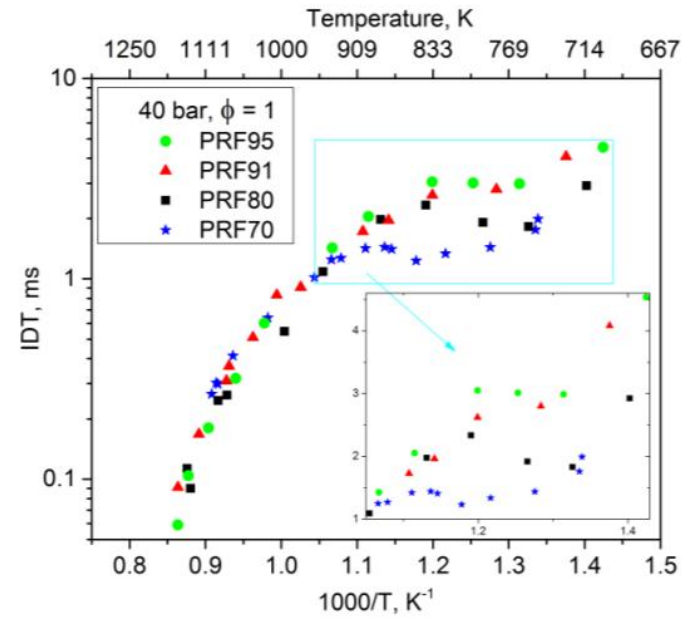

(a)

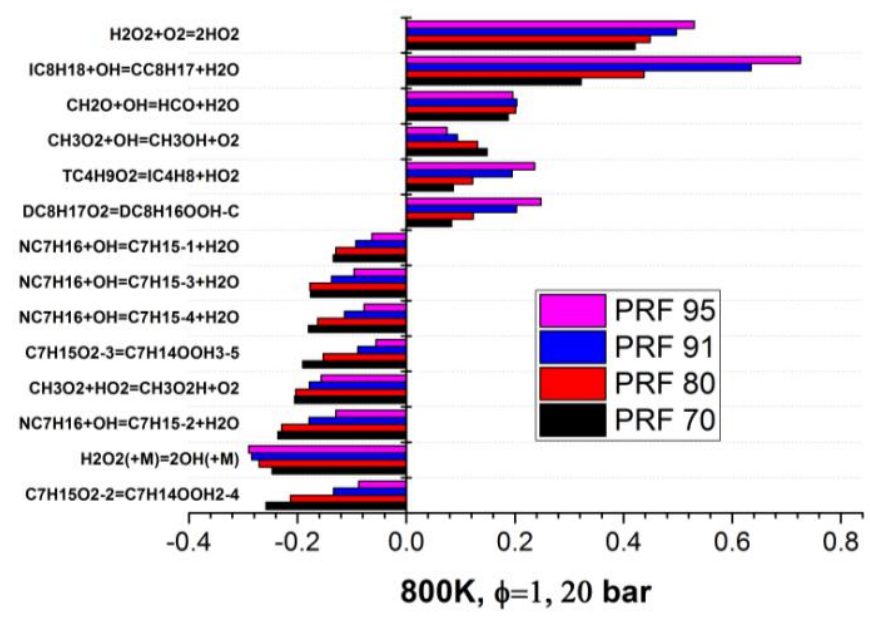

(b)

Fig. 8. Influence of fuel composition on ignition delay times. (a) comparison among the four PRF blends at 40 bar and $\phi=1$, (b) brute force sensitivity analysis comparison for the four blends at $20 \mathrm{bar}, \phi=1$ and $800 \mathrm{~K}$. The inset in (a) shows ignition delay times on a linear scale to illustrate the composition dependence.

Fig. 8(b) presents the sensitivity analyses of PRF 70, 80, 91, 95 at 20 bar and $800 \mathrm{~K}$ for stoichiometric mixture. It can be observed that $\mathrm{H}$-abstraction reactions of $\mathrm{n}$-heptane and isooctane compete for the hydroxyl radicals. The inhibiting effect of iso-octane increases as the fraction of iso-octane increases in the fuel blend which results in overall decreased the reactivity of the system.

\subsection{Comparison with Chemical Kinetic Models}

Fig. 9(a) presents comparison between the four kinetic models and the experimental data for PRF 70 at $\phi=1$ and pressures of 10, 20 and 40 bar. At temperatures higher than $1000 \mathrm{~K}$, experimental data agree well with all mechanisms except Cai et al. [48] which appears to be slightly faster. At lower temperatures and in the NTC region, the agreement between 
measurements and models varies. For example, the 20 bar data agree quite well with the predictions of Mehl et al. [45] models. On the other hand, the 40 bar data agreed well with the predictions of the optimized model of Cai et al. [48].

Fig. 9(b) compares experimental data and model predictions for PRF 70 at pressure of 40 bar and two equivalence ratios $(\phi=0.5,1)$. At high temperatures, in contrast to all models, the experimental data exhibit very weak equivalence ratio dependence. At lower temperatures, stoichiometric PRF 70 data compare very well with the predictions of Cai et al. [48] mechanism. Ignition delay times for lean mixture seem to be overestimated by all mechanisms in the NTC and low-temperature region.

The performance of various mechanisms in predicting fuels of varying composition is shown in Fig. 9(c), which plots data for PRF 70 and 95 at pressure of 40 bar and $\phi=1$. In the hightemperature region, experimental data agree quite well with the four mechanisms. However, in the NTC and low-temperature regions, the experimental data agree better with the prediction of Cai et al. [48] model.

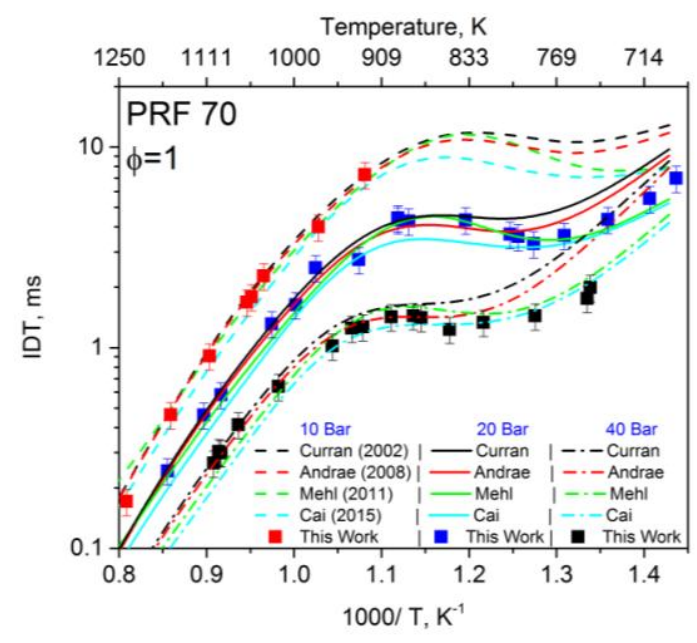

(a)

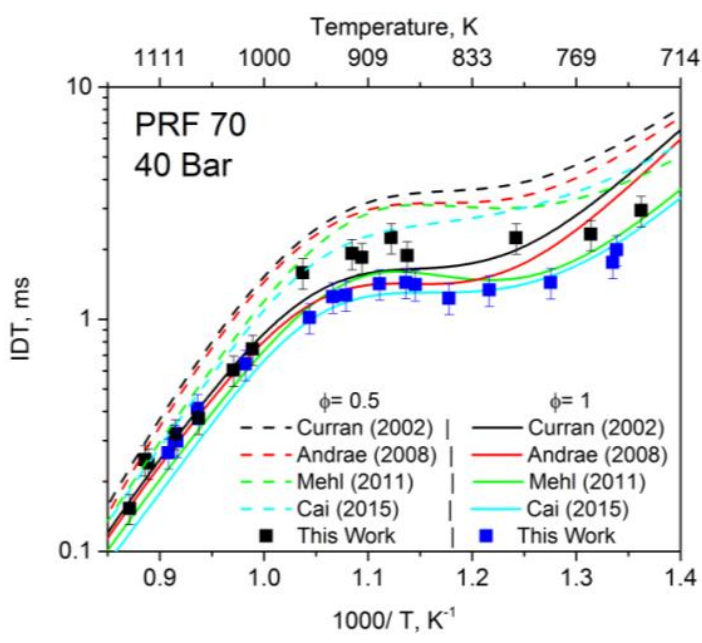

(b) 


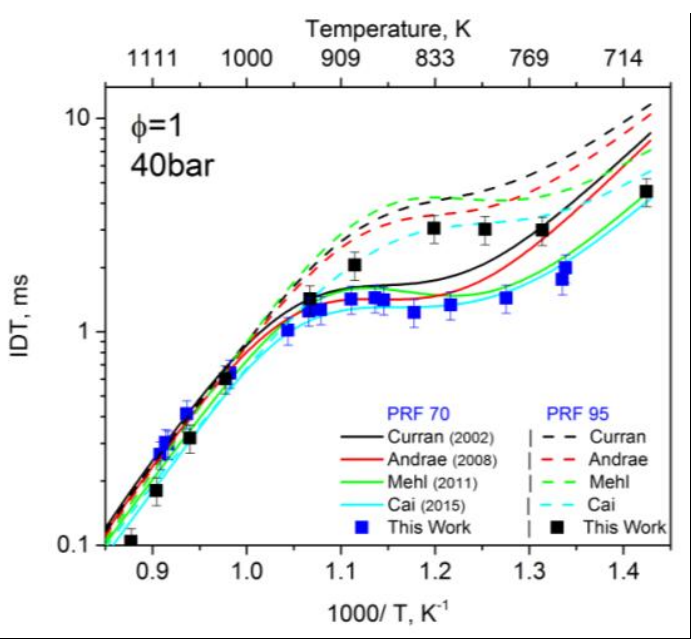

(c)

Fig. 9. Comparison of measured ignition delay times with the predictions of four kinetic mechanisms: Mehl et al. [45], Cai et al. [48], Curran et al. [33], Andrae et al. [40].

In general, the mechanism by Cai et al. [48] shows better agreement with experimental data over a broader range of conditions. This is due to the fact that this model is developed by optimizing rate coefficient rules with the help of literature ignition delay data of n-heptane, iso-octane and PRF mixtures. Further detailed comparisons of our experimental ignition delay times and model predictions are provided in Fig. $S 9(a-x)$ of the Supplementary Material.

Ignition delay time sensitivity analyses were conducted for the four kinetic mechanisms at $800 \mathrm{~K}$ and 20 bar for PRF 70 stoichiometric mixture; results for the top five reactions are plotted in Fig. 10. The selected condition falls in the NTC region. The mechanisms place varying levels of importance to the critical reactions. The competition between hydrogen peroxide $\left(\mathrm{H}_{2} \mathrm{O}_{2}\right)$ decomposition and the reaction of hydrogen peroxide with oxygen dictates the reactivity of the system. $\mathrm{H}$-abstraction by $\mathrm{OH}$ from n-heptane promotes reactivity while $\mathrm{H}$-abstraction from isooctane inhibits reactivity. This competition for hydroxyl radicals is important in all mechanisms except Cai et al. [48]. On the other hand, Cai et al. [48] model places much greater emphasis on the isomerization of $\mathrm{RO}_{2}$ radicals to $\mathrm{QOOH}$. 


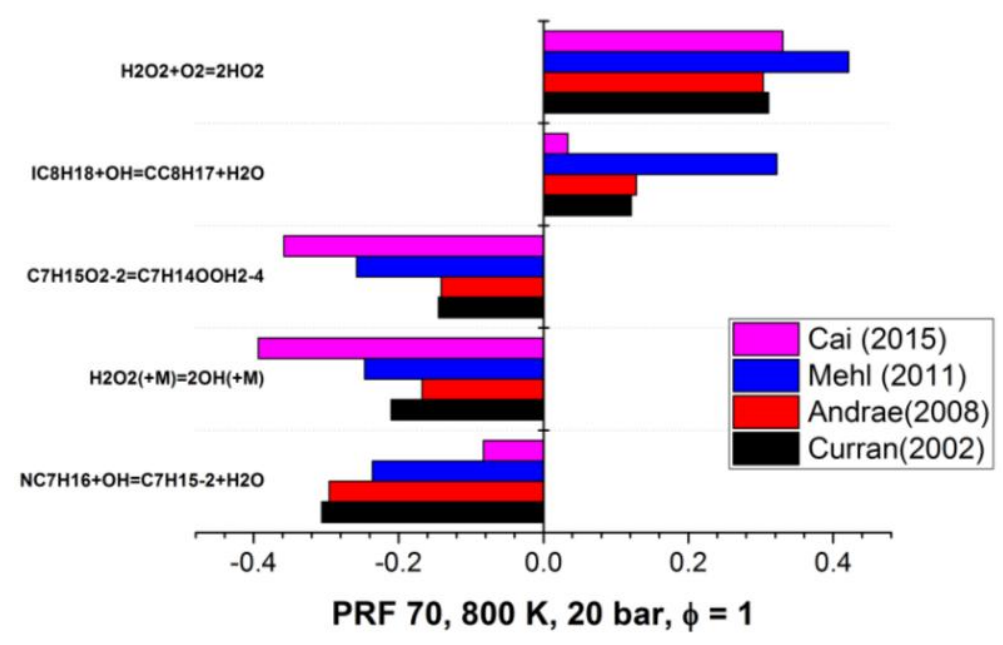

Fig. 10. Ignition delay times sensitivity analyses for the four chemical kinetic models.

\subsection{Pre-ignition Energy Release}

Shock tube ignition delay data at relatively long ignition delay times may be affected by nonideal phenomena such as gradual pressure increase behind reflected shock wave and pre-ignition energy release. Davidson et al. [16] observed pre-ignition energy release in iso-octane/air and toluene/air mixtures and considered this behavior to be due to a chemical kinetic process not predicted by the chemistry models. Mittal et al. [55] presented additional data on toluene/air ignition in a rapid compression machine and showed no evidence of pre-ignition activity. They speculated that wall contamination might be responsible for pre-ignition phenomena. Vasu et al. [56] re-examined toluene ignition delays and concluded that contamination was not the source of the pre-ignition observed by Davidson et al. [16]. They conclude that pre-ignition phenomena can be connected to mild, strong, and mild-to-strong ignition regimes. This conclusion is consistent with the observation of localized ignition in the mild and transition regimes in other shock tube studies. Recently, Troutman et al. [57] used high speed $\mathrm{OH}^{*}$ chemiluminescence imaging to study pre-ignition during the combustion of n-heptane and attributed pre-ignition to the shock tube wall contamination and shock / boundary-layer interactions.

In the current work, all pressure profiles were analyzed in detail to alleviate any shortening of ignition delay times by pre-ignition energy release. At the low temperatures of the current work, some pressure and $\mathrm{OH}^{*}$ emission-time profiles did exhibit evidence of pre-ignition energy release. However, further analyses revealed that such pre-ignition energy release had negligible 
effect on the ignition delay time data reported here. As a representative illustration, Fig. 11(a) presents pressure time-histories of two ignition delay time measurements for stoichiometric mixture of PRF 80 at $\sim 10$ bar. The two pressure profiles exhibit varying amounts of pre-ignition energy release with the green trace showing relatively small pressure rise before autoignition (exponential pressure rise) and the black solid trace showing considerably larger pressure rise before bulk ignition. These measurements points are marked correspondingly in the Arrhenius plot in Fig. 11(b). The expected placement of the two ignition delay time data points along the high-temperature Arrhenius line indicates that these measurements were negligibly affected by the pre-ignition energy release.

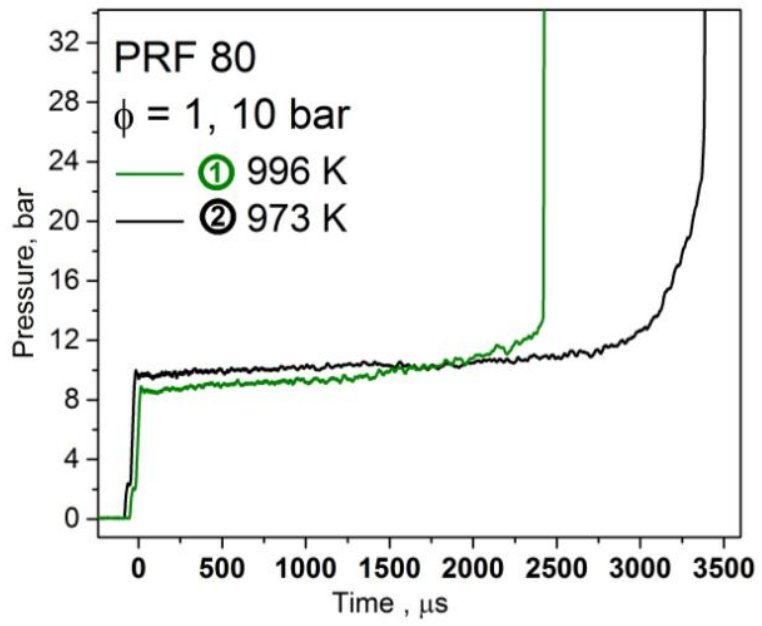

(a)

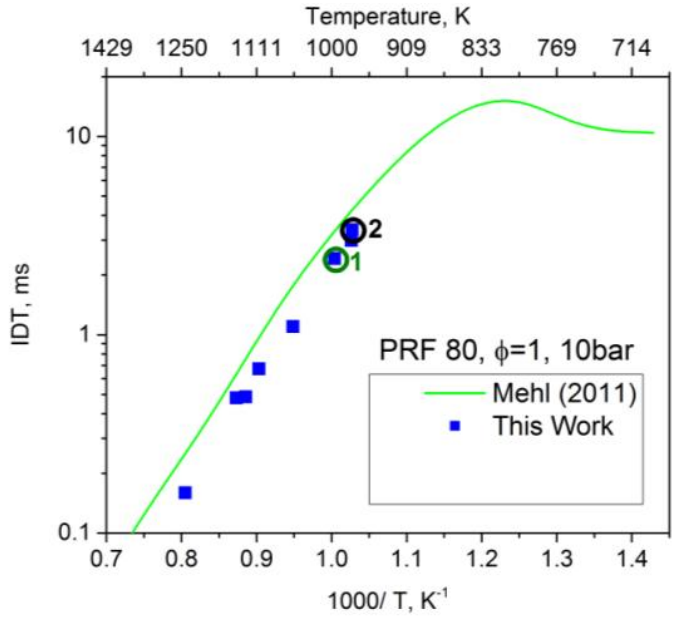

(b)

Fig. 11. Pre-ignition effect on igniting delay time. (a) Pressure- time history with and without evidence of weak pre-ignition energy release for stoichiometric mixture of PRF 80 at 10 bar. (b) Ignition delay times for stoichiometric mixture of PRF 80 at 10 bar.

\section{Conclusions}

Ignition delay times for PRF 70, 80, 91 and 95 were measured over a wide range of temperatures, pressures and two equivalence ratios. The extensive measurements provide detailed validation targets for testing the fidelity of the chemical kinetic mechanisms of $n$ heptane/iso-octane blends. Measured ignition delay times from this study were compared to the predictions of four different kinetic mechanisms: Mehl et al. [45], Cai et al.[48], Curran et al. [33], and Andrae et al. [40]. Overall, good agreement among the data and models was observed 
at high and moderate temperatures. However, the agreement varies in the NTC and lowtemperature regions based on the pressure, composition and equivalence ratio. Pressure appears to have a significant effect on the ignition delay times and this effect is amplified in the NTC region compared to the high and low temperatures. The effect of equivalence ratio and composition on the ignition delay time is also larger in the NTC region. Ignition delay time correlations were developed to fit the measured ignition delays over the wide range of experimental conditions. Such correlations can be quite useful in the simulation-based design of modern engines. We believe that the extensive reactivity data obtained in this work will serve as a benchmark for detailed and reduced gasoline surrogate models.

\section{Acknowledgement}

We would like to acknowledge the funding support from Saudi Aramco under the FUELCOM program and by King Abdullah University of Science and Technology (KAUST). 


\section{Supplementary Material}

Table S1. Measured ignition delay times and corresponding conditions. All data were measured in fuel/air mixtures.

Fig. S1 $(a-x)$. Additional comparisons of measured ignition delay times with predictions of four kinetic mechanisms.

Fig. S1. Error between fitted and measured ignition delay times.

Fig. S2 (a - b). Comparison between the pressure dependence exponents (n) calculated from experiments and simulations.

Fig. S3 (a - b). Temperature sensitivity analyses for stoichiometric mixture of PRF 70 at 1100 and $1200 \mathrm{~K}$.

Fig. S4. Comparison between the pressure exponents of the four PRF blends at $1100 \mathrm{~K}$.

Fig. S5. Temperature sensitivity analysis for stoichiometric mixtures of PRF 70 and 95.

Fig. S6 $(\mathrm{a}-\mathrm{d})$. Pressure dependence exponents for stoichiometric mixture of PRF 70 at $10-20$ bar and $20-40$ bar pressure ranges.

Fig. S7. Temperature sensitivity analysis of lean and stoichiometric mixtures of PRF 70.

Fig. S8 $(\mathrm{a}-\mathrm{d})$. Equivalence ratio exponents for stoichiometric mixture of PRF 70 at 10, 20 and 40 bar.

Fig. S9 $(a-x)$. Additional comparisons of measured ignition delay times with the predictions of four kinetic mechanisms. 


\section{References}

[1] R. Stone, Introduction to Internal Combustion Engines, The Macmillan Press LTD, SAE International and Macmillan Press, London, 1992.

[2] C. Hudson, X. Gao, R. Stone, Knock measurement for fuel evaluation in spark ignition engines, Fuel 80 (2001) 395-407.

[3] K. Fieweger, R. Blumenthal, G. Adomeit, Self-ignition of S.I. engine model fuels: A shock tube investigation at high pressure, Combustion and Flame 109 (1997) 599-619.

[4] J. Heywood, Internal Combustion Engines Fundamentals, McGraw-Hill, London, 1988.

[5] G.T. Kalghatgi, Developments in internal combustion engines and implications for combustion science and future transport fuels, Proceedings of the Combustion Institute 35 (2015) 101-115.

[6] S. Jerzembeck, N. Peters, P. Pepiot-Desjardins, H. Pitsch, Laminar burning velocities at high pressure for primary reference fuels and gasoline: Experimental and numerical investigation, Combustion and Flame 156 (2009) 292-301.

[7] T. Javed, E.F. Nasir, E.-t. Es-sebbar, A. Farooq, A comparative study of the oxidation characteristics of two gasoline fuels and an n-heptane/iso-octane surrogate mixture, Fuel 140 (2015) 201-208.

[8] T. Javed, E.F. Nasir, A. Ahmed, J. Badra, K. Djebbi, M. Beshir, W. Ji, S.M. Sarathy, A. Farooq, Ignition delay measurements of light naphtha: A fully blended low octane fuel, Proceedings of the Combustion Institute, (2016).

[9] J. Badra, A. Elwardany, J. Sim, Y. Viollet, H. Im, J. Chang, Effects of In-Cylinder Mixing on Low Octane Gasoline Compression Ignition Combustion, Report No. 0148-7191, SAE Technical Paper, 2016. [10] A. Ahmed, G. Goteng, V.S. Shankar, K. Al-Qurashi, W.L. Roberts, S.M. Sarathy, A computational methodology for formulating gasoline surrogate fuels with accurate physical and chemical kinetic properties, Fuel 143 (2015) 290-300.

[11] G. Kalghatgi, H. Babiker, J. Badra, A simple method to predict knock using toluene, n-heptane and iso-octane blends (TPRF) as gasoline surrogates, SAE International Journal of Engines 8 (2015) 505-519. [12] G. Kalghatgi, R. Head, J. Chang, Y. Viollet, H. Babiker, A. Amer, An alternative method based on toluene/n-heptane surrogate fuels for rating the anti-knock quality of practical gasolines, SAE International Journal of Fuels and Lubricants 7 (2014) 663-672.

[13] D.J. Vermeer, J.W. Meyer, A.K. Oppenheim, Auto-ignition of hydrocarbons behind reflected shock waves, Combustion and Flame 18 (1972) 327-336.

[14] C. Coats, A. Williams, Seventeenth Symposium (International) on Combustion, The Combustion Institute, Pittsburgh, (1979) 611.

[15] H. Ciezki, G. Adomeit, Shock-tube investigation of self-ignition of n-heptane-air mixtures under engine relevant conditions, Combustion and flame 93 (1993) 421-433.

[16] D.F. Davidson, B.M. Gauthier, R.K. Hanson, Shock tube ignition measurements of iso-octane/air and toluene/air at high pressures, Proceedings of the Combustion Institute 30 (2005) 1175-1182.

[17] A.B. Mansfield, M.S. Wooldridge, H. Di, X. He, Low-temperature ignition behavior of iso-octane, Fuel 139 (2015) 79-86.

[18] B.M. Gauthier, D.F. Davidson, R.K. Hanson, Shock tube determination of ignition delay times in fullblend and surrogate fuel mixtures, Combustion and Flame 139 (2004) 300-311.

[19] M. Hartmann, I. Gushterova, M. Fikri, C. Schulz, R. SchießI, U. Maas, Auto-ignition of toluene-doped n-heptane and iso-octane/air mixtures: High-pressure shock-tube experiments and kinetics modeling, Combustion and Flame 158 (2011) 172-178.

[20] R. Minetti, M. Carlier, M. Ribaucour, E. Therssen, L.R. Sochet, A rapid compression machine investigation of oxidation and auto-ignition of n-Heptane: Measurements and modeling, Combustion and Flame 102 (1995) 298-309. 
[21] J. Herzler, L. Jerig, P. Roth, Shock tube study of the ignition of lean n-heptane/air mixtures at intermediate temperatures and high pressures, Proceedings of the Combustion Institute 30 (2005) 11471153.

[22] P. Dagaut, M. Reuillon, M. Cathonnet, High Pressure Oxidation of Liquid Fuels From Low to High Temperature. 1. n-Heptane and iso-Octane, Combustion Science and Technology 95 (1993) 233-260. [23] H.-P.S. Shen, J. Steinberg, J. Vanderover, M.A. Oehlschlaeger, A shock tube study of the ignition of n-heptane, n-decane, n-dodecane, and n-tetradecane at elevated pressures, Energy \& Fuels 23 (2009) 2482-2489.

[24] D.F. Davidson, M.A. Oehlschlaeger, R.K. Hanson, Methyl concentration time-histories during isooctane and n-heptane oxidation and pyrolysis, Proceedings of the Combustion Institute 31 (2007) 321328.

[25] D.F. Davidson, Z. Hong, G.L. Pilla, A. Farooq, R.D. Cook, R.K. Hanson, Multi-species time-history measurements during n-heptane oxidation behind reflected shock waves, Combustion and Flame 157 (2010) 1899-1905.

[26] Y. Sakai, H. Ozawa, T. Ogura, A. Miyoshi, M. Koshi, W.J. Pitz, Effects of toluene addition to primary reference fuel at high temperature, Report No. 0148-7191, SAE Technical Paper, 2007.

[27] T. Javed, C. Lee, M. AlAbbad, K. Djebbi, M. Beshir, J. Badra, H. Curran, A. Farooq, Ignition studies of n-heptane/iso-octane/toluene blends, Combustion and Flame 171 (2016) 223-233.

[28] S.M. Sarathy, G. Kukkadapu, M. Mehl, W. Wang, T. Javed, S. Park, M.A. Oehlschlaeger, A. Farooq, W.J. Pitz, C.-J. Sung, Ignition of alkane-rich FACE gasoline fuels and their surrogate mixtures, Proceedings of the Combustion Institute 35 (2015) 249-257.

[29] C.K. Westbrook, J. Warnatz, W.J. Pitz, A detailed chemical kinetic reaction mechanism for the oxidation of iso-octane and $\mathrm{n}$-heptane over an extended temperature range and its application to analysis of engine knock, Symposium (International) on Combustion 22 (1989) 893-901.

[30] E. Ranzi, P. Gaffuri, T. Faravelli, P. Dagaut, A wide-range modeling study of $n$-heptane oxidation, Combustion and Flame 103 (1995) 91-106.

[31] E. Ranzi, T. Faravelli, P. Gaffuri, A. Sogaro, A. D'Anna, A. Ciajolo, A wide-range modeling study of isooctane oxidation, Combustion and Flame 108 (1997) 24-42.

[32] H.J. Curran, P. Gaffuri, W.J. Pitz, C.K. Westbrook, A Comprehensive Modeling Study of n-Heptane Oxidation, Combustion and Flame 114 (1998) 149-177.

[33] H.J. Curran, P. Gaffuri, W.J. Pitz, C.K. Westbrook, A comprehensive modeling study of iso-octane oxidation, Combustion and Flame 129 (2002) 253-280.

[34] S. Tanaka, F. Ayala, J.C. Keck, A reduced chemical kinetic model for $\mathrm{HCCl}$ combustion of primary reference fuels in a rapid compression machine, Combustion and flame 133 (2003) 467-481.

[35] M. Jia, M. Xie, A chemical kinetics model of iso-octane oxidation for $\mathrm{HCCl}$ engines, Fuel 85 (2006) 2593-2604.

[36] G.L. Agafonov, I. Naydenova, P.A. Vlasov, J. Warnatz, Detailed kinetic modeling of soot formation in shock tube pyrolysis and oxidation of toluene and $n$-heptane, Proceedings of the Combustion Institute 31 (2007) 575-583.

[37] S.S. Ahmed, Mau, G. Moreac, T. Zeuch, A comprehensive and compact $n$-heptane oxidation model derived using chemical lumping, Physical Chemistry Chemical Physics 9 (2007) 1107-1126.

[38] P. Kirchen, M. Shahbakhti, C.R. Koch, A SKELETAL KINETIC MECHANISM FOR PRF COMBUSTION IN HCCI ENGINES, Combustion Science and Technology 179 (2007) 1059-1083.

[39] T. Ogura, Y. Sakai, A. Miyoshi, M. Koshi, P. Dagaut, Modeling of the Oxidation of Primary Reference Fuel in the Presence of Oxygenated Octane Improvers: Ethyl Tert-Butyl Ether and Ethanol, Energy \& Fuels 21 (2007) 3233-3239.

[40] J.C.G. Andrae, Development of a detailed kinetic model for gasoline surrogate fuels, Fuel 87 (2008) 2013-2022. 
[41] J.C.G. Andrae, T. Brinck, G.T. Kalghatgi, $\mathrm{HCCl}$ experiments with toluene reference fuels modeled by a semidetailed chemical kinetic model, Combustion and Flame 155 (2008) 696-712.

[42] Y. Ra, R.D. Reitz, A reduced chemical kinetic model for IC engine combustion simulations with primary reference fuels, Combustion and Flame 155 (2008) 713-738.

[43] Y. Sakai, A. Miyoshi, M. Koshi, W.J. Pitz, A kinetic modeling study on the oxidation of primary reference fuel-toluene mixtures including cross reactions between aromatics and aliphatics, Proceedings of the Combustion Institute 32 (2009) 411-418.

[44] K. Lee, Y. Kim, K. Min, Development of a reduced chemical kinetic mechanism for a gasoline surrogate for gasoline $\mathrm{HCCl}$ combustion, Combustion Theory and Modelling 15 (2010) 107-124.

[45] M. Mehl, W.J. Pitz, C.K. Westbrook, H.J. Curran, Kinetic modeling of gasoline surrogate components and mixtures under engine conditions, Proceedings of the Combustion Institute 33 (2011) 193-200.

[46] Y.-D. Liu, M. Jia, M.-Z. Xie, B. Pang, Enhancement on a Skeletal Kinetic Model for Primary Reference Fuel Oxidation by Using a Semidecoupling Methodology, Energy \& Fuels 26 (2012) 7069-7083.

[47] H. Wang, M. Yao, R.D. Reitz, Development of a Reduced Primary Reference Fuel Mechanism for Internal Combustion Engine Combustion Simulations, Energy \& Fuels 27 (2013) 7843-7853.

[48] L. Cai, H. Pitsch, Optimized chemical mechanism for combustion of gasoline surrogate fuels, Combustion and Flame 162 (2015) 1623-1637.

[49] R.J. Kee, F.M. Rupley, J.A. Miller, The Chemkin thermodynamic data base, Report No. SAND-878215B, Sandia National Lab, Livermore, CA (USA),

[50] R. CHEMKIN-PRO, 15112, Reaction Design, Inc., San Diego, CA, (2011).

[51] W.K. Metcalfe, S.M. Burke, S.S. Ahmed, H.J. Curran, A Hierarchical and Comparative Kinetic Modeling Study of C1 - C2 Hydrocarbon and Oxygenated Fuels, International Journal of Chemical Kinetics 45 (2013) 638-675.

[52] G.A. Weisser, Modelling of combustion and nitric oxide formation for medium-speed DI diesel engines, Diss., Technische Wissenschaften ETH Zürich, Nr. 14465, 2002, 2001.

[53] J. Ma, K.H. Kwak, B. Lee, D. Jung, An empirical modeling approach for the ignition delay of fuel blends based on the molar fractions of fuel components, Fuel 164 (2016) 305-313.

[54]

J. Livengood, P. Wu. Correlation of autoignition phenomena in internal combustion engines and rapid compression machines. In: editor^editors. Symposium (International) on Combustion; 1955: Elsevier. p. 347-356.

[55] G. Mittal, C.-J. Sung, Autoignition of toluene and benzene at elevated pressures in a rapid compression machine, Combustion and Flame 150 (2007) 355-368.

[56] S.S. Vasu, D.F. Davidson, R.K. Hanson, Shock-Tube Experiments and Kinetic Modeling of Toluene Ignition, Journal of propulsion and power 26 (2010) 776-783.

[57] V. Troutman, C. Strand, M. Campbell, A. Tulgestke, V. Miller, D. Davidson, R. Hanson, High-speed $\mathrm{OH}^{*}$ chemiluminescence imaging of ignition through a shock tube end-wall, Applied Physics B 122 (2016) 1-7. 
Supplementary Material
Click here to download S

Click here to download Supplementary Material: Supp Materials v6 Not Highlighted.docx

(1)

$\sqrt{3}$

(1)

(1)

$\sqrt{2}$

.

(1)

.

.

.

.

.

.

.

.

.

.

.

.

.

.

.

.

.

.

.

.

.

.

.

.

.

.

.

.

.

.

. 